\title{
STUDY ON THE TECHNOLOGY AND METHOD OF LAND COVER CLASSIFICATION FOR GEOGRAPHIC NATIONAL CONDITIONS SURVEYING*
}

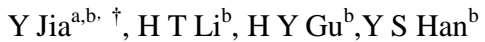 \\ ${ }^{a}$ Institute of Surveying and Geography Science, Liaoning University of Engineering and Technology, Fuxin, China- \\ jy6465@126.com \\ ${ }^{\mathrm{b}}$ Chinese Academy of Surveying and Mapping, Beijing, China-lhtao@casm.ac.cn
}

KEY WORDS:Land cover, Classification technology, Geographic national conditions surveying, Classification strategy

\begin{abstract}
:
Land Cover is the basis of geographic national conditions monitoring, extracting land cover information timely and accurately has become one of important tasks in the geographic national conditions surveying project. For the current situation of complex land cover type and large amount of data, there has emerged various new classification techniques and methods. However, the big difficult of classification, the large amount of data, the heavy workload of post-editing and other factors have seriously hampered the progress of the project. In this paper, it chooses high-resolution remote sensing image as original data, comprehensivly elaborates present research situation of oriented land cover classification. By the systematical analysis and summary of the basic and key problems of the land cover classification technology, relying on the geographic national information classification and standard system, discusses the available methods preliminarily to improve the accuracy of land cover classification which based on geographic national conditions surveying.
\end{abstract}

\section{INTRODUCTION}

Geographic national conditions as China's basic and important condition, geographic national conditions surveying has become an important means of obtaining national conditions and power information, it is also the integrated and fundamental work to master the natural resources, ecological environment and human activities.Among them, land cover is the basis of geographic national conditions monitoring, extracting land cover information timely and accurately has become one of important tasks in the geographic national conditions surveying project.High-resolution remote sensing imagery, as the major original data of land cover classification, include satellite or aerial photography imagery with phase of no earlier than 2011, ground resolution of $1 \mathrm{~m}, 2.5 \mathrm{~m}$ or $5 \mathrm{~m}$ of partial area.Because of the inconsistency of classification system, basic geographic information data can not meet the needs of the surveying.During the pilot work of geographic national conditions surveying, due to the complex land cover types, the vast processed data, various surveying standard and lacking of uniform and effective platform to support the project construction, the existing classification software and classification methods and strategies have the problems of lower classification accuracy and more manual post- editing workload and so on, thus it is difficult to ensure the project progress and quality. Nowadays, the studies on improving the classification accuracy are focused on proposing new algorithms, but post-editing is still a great deal work and it is difficult to meet the needs of practical applications. Therefore, the paper chooses high-resolution remote sensing imagery as original data, comprehensivly elaborates present research situation of oriented land cover classification. By the systematical analysis and summary of the basic and key problems of the land cover classification technology, relying on the geographic national information classification and standard system, discusses the available methods preliminarily to improve the accuracy of land cover classification which based on geographic national conditions surveying.

\section{TECHNICAL SCHEME OF LAND COVER CLASSIFICATION FOR GEOGRAPHIC NATIONAL CONDITIONS SURVEYING}

Since the launching of geographic national conditions surveying project, various research and production institution are exploring technical schemes of land cover classification for geographic national conditions surveying constantly, which relying on the content and index of geographic national conditions surveying.

\subsection{Land cover classification based on eCognition}

First of all, high-resolution remote sensing image is segmented.Considering the spectral features,shape features, texture features and feature attributes between objects comprehensively, at the same time, supplementing houses and roads DLG data to construct interpreted rule sets manually, thus completing land cover classification.

Disadvantages: The interpreted rule sets need professionals to complete and have poor universality for different image phase, data sources and regions. They can't control the multi-level classification category.

2.2 Land cover classification based on ENVI_EX (Feature Extraction)

Using Feature Extraction, which is the core functional module

\footnotetext{
* The paper is a sub-content of the technical platform of geographic national conditions monitoring, which is a national science and technology support subject and the number is 2012BAH28B03.

${ }^{\dagger}$ Corresponding author at: Chinese Academy of Surveying and Mapping, No.28 Lianhuachixi RD, Haidian District, Beijing 100830, China.

E-mail address: jy6465@126.com.
} 
of object-oriented feature extraction tool ENVI_EX, to segment and merge the image on a certain scale and then to class by selecting samples or building rule sets.

Disadvantages: There have only three kinds of features (spectrum, texture, shape) for selection and the segmentation effect is not good, which affect the classification effect directly.Meanwhile,the establishment of rule sets requires professionals to complete and it does not support vector to participate in classification.

\subsection{Land cover classification based on Erdas (Feature Analyst)}

In order to extract and analyze all the specific objects of the image, it uses machine-learning feature recognition method which based on statistics and no segmentation,takes specific object as extracting target, meanwhile combines with spatial information based on pixel-level,

Disadvantages:The grading settings and preferences selection need professionals to complete and it does not support the existing vector in classification.

\subsection{Land cover classification based on PCI ( Feature Objex)}

FeatureObjeX provides intelligent spatial feature extraction tool.Instead of segmentation, it extractes target feature from the raster image directly which based on color, texture, shape and pixel values.

Disadvantages: The operation is complicated and it does not support the existing vector in classification.

2.5 Land cover classification based on FeatureStation GeoEX

Relying on content and standard of geographic national conditions surveying, a sequence of image segmentation, sample collection, feature extraction, image classification, classification post-editing and accuracy assessment to complete the land cover classification.

Disadvantages: The sample collection is relatively cumbersome. To sum up, although land cover classification based on eCognition is widely used in the pilot work of geographic national conditions surveying, the slow speed of segmentation, writing rule sets complexly, high technical threshold, poor universality and the volume of human intervention result in the difficulty to ensure the progress and quality of the geographic national conditions surveying. Land cover classification based on ENVI_EX (Feature Extraction), Erdas, PCI is hard to work productively. Although the manual interpretation can get better classification results, the low efficiency, the unportability of classification techniques, and human error can not reflect the real purpose of the image, those all lead to the result of not meeting the surveying requirements.FeatureStation GeoEX support the hierarchical stepwise classification method which in line with workers' thinking progressively, the low technical threshold and processoriented operation mode can meet the requirements of land cover classification.

\section{KEY TECHNOLOGY OF LAND COVER CLASSIFICATION FOR GEOGRAPHIC NATIONAL CONDITIONS SURVEYING}

According to the basic issue of low land cover classification accuracy and the heavy workload of post-editing, as well as the key issue of the disunity of technology and progress, based on the function and characteristics of eCognition and FeatureStation GeoEX, this section analyzes from objectoriented classification techniques, classification strategies, land cover classification comprehensively and provides experimental and technical support for land cover classification accordingly.

\subsection{Multi-segmentation}

Image segmentation is the key to object-oriented information extraction technology and is the first step of object-oriented remote sensing image classification, and the delineation quality of the target objects has a direct influence on the accuracy of the subsequent image classification. The multiresolution image segmentation(MRIS) which based on fractal net evolution approach (FNEA) algorithm is the basic and core content of the corrent object-oriented image analysis technology.MRIS is a region-growing segmentation algorithm which starting from individual pixels, using the bottom-up region merging method to form objects, following the principle of minimum heterogeneity,and forming a multi-scale network hierarchy in the end.

Image segmentation is performed at multi-scales, thus forming image object hierarchy determined by scale parameters. A image object integrates pixel' spectral information and the relationship information with the surrounding pixels. In multi-segmentation, each object layer has its own fixed scale, multiple object hierarchy can reflect the surface feature' classic attribute which having various spatial scales, and extract different attributive class at different scale layer, thereby solving the problem of different types resulting from identitying all spatial attributes at the same resolution image. It is obtained from large number of experiments and studies in the pilot work of geographic national conditions surveying and research work that according to the specific surface features, the segmentation scale should be set between 50200for high-resolution imagery which the resolution is $0.5 \mathrm{~m}$ between $2 \mathrm{~m}$, and more smaller,more fragmentary of the surface features, that is more larger, the adjacent surface features are different to separate, which is not conducive to the post-editing. Therefore, quantifying suitable segmentation scale for different surface features and achieving scale adaptive technology has important theoretical and practical significance.

\subsection{Extraction and analysis of object feature}

Extraction of image object is performed subsequent to the image segmentation, which based on the segmented vector objects.The relationship between image features and the class characteristic of land cover elements is realized by various feature extraction methods. With the feature extraction, it provides classification feature basis for subsequent image classification.

So far, decision tree, random forest and SVM algorithm are easier to use and have higher classification accuracy. The decision tree and random forest algorithm-self can select optimal characteristics automatically.For small samples,SVM 
has good classification effect, but it can't select optimal features automatically. In the mass of features, selecting optimal combination of features for each feature and set threshold.During the process of classification, in order to improve the efficiency of feature extraction and classification accuracy, we extract the key features according to different class and avoid some invalid features.

\begin{tabular}{|l|l|}
\hline Surface feature types & Common features and analysis \\
\hline Water & $\begin{array}{l}\text { The water has low reflectance rate in the near-infrared(NIR) band and shows dark tones in the } \\
\text { image. It is often used near-infrared-related features, such as mean value of NIR, NDVI, NDWI } \\
\text { and so on. } \\
\text { Road shows long strip on the shape so that shape features are used constantly,which are border } \\
\text { index, density, length-width ratio, etc., meanwhile, brightness and mean value of each band can } \\
\text { be used } \\
\text { The most common feature is NDVI,that of others such as ratio of green band, standard deviation } \\
\text { of NIR,texture features.Meanwhile,it also uses NIR band to distinguishe cultivated land from } \\
\text { vegetation.DEM data is often used to extract woodland in the mountainal region. } \\
\text { Vuildings have high reflectance rate in each band and shows bright tones in the image.The group } \\
\text { of bulidings' surface is rough,the standard deviation of each band is larger relatively.So that,it } \\
\text { irrigated land) } \\
\text { Buildings } \\
\text { can use brightness value, mean value of each band and the standard deviation of each band } \\
\text { during classification. } \\
\text { Those surface features generally have no vegetation covering, the high reflectance rate lead to } \\
\text { the bright tones shown in the image.Therefore it generally uses brightness value and mean value } \\
\text { of each band. }\end{array}$ \\
$\begin{array}{l}\text { Artificial pile digging } \\
\text { area_structure_bare surface }\end{array}$
\end{tabular}

Table 1 . The feature analysis for geographic national conditions surveying

\subsection{Land cover classification strategy for geographic national conditions surveying}

Comparing with traditional pixel-based classification, the object-oriented classification method has great advantage and higher classification accuracy. According to the existing methods, if uses a single classification model, the classification results may not be able to achieve better classification effect. Against this disadvantage, the study adopts stratified, zoned and graded processing mode, from low to high (easy to difficult) to porform the classification according to the separating error of land cover types which is the degree of classification difficulty. The mode is namely the hierarchical stepwise subdivision classification strategy.

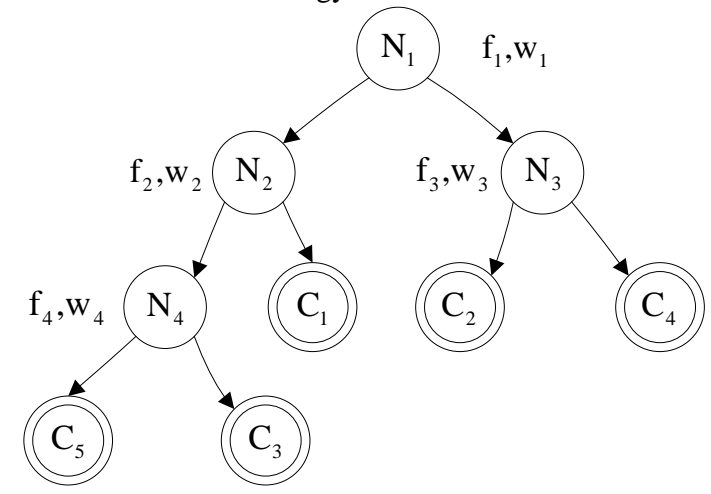

\subsection{Workflow of land cover classification}

According to the data and the contents and indexes of geographic national conditions surveying, as well as the land cover classification scheme and technical requirement,it creates technical processes of object-oriented classification which is based on sample training guid production operation. The main originaldata of geographic national conditions surveying is the multi-source highresolution remote sensing image, so that we can't use traditional classification technology during making the
Figure 1. Establish the hierarchical classification tree.

$\mathrm{N}_{1}, \ldots \mathrm{N}_{4}$ are the root nodes of the classification tree, $\mathrm{f}_{1}, \ldots$ $\mathrm{f}_{2}$ are the decision rules, $\mathrm{C}_{1}, \ldots \mathrm{C}_{4}$ are the final classification resaults.

According to the basic idea of hierarchical decision tree and taking the extraction capability and difficulty level of each surface feature and the relationship between land cover types into account adequately,the study creates object-oriented hierarchical stepwise subdivision classification strategy(Figure 2).

classification process. In this paper, the classification procedure (Figure 3 and Figure 4) is based on the objectoriented classification technology. Using multi-

scale segmentation technology to turn high resolution remote se nsing imagery into homogeneous image objects, using the train ing sample data which were collected through the feature infor mation, using decision tree, SVM and random forest algorithm to finish the automatic classification of land cover surface features. 
International Archives of the Photogrammetry, Remote Sensing and Spatial Information Sciences, Volume XL-7/W1, 3rd ISPRS IWIDF 2013, 20 - 22 August 2013, Antu, Jilin Province, PR China

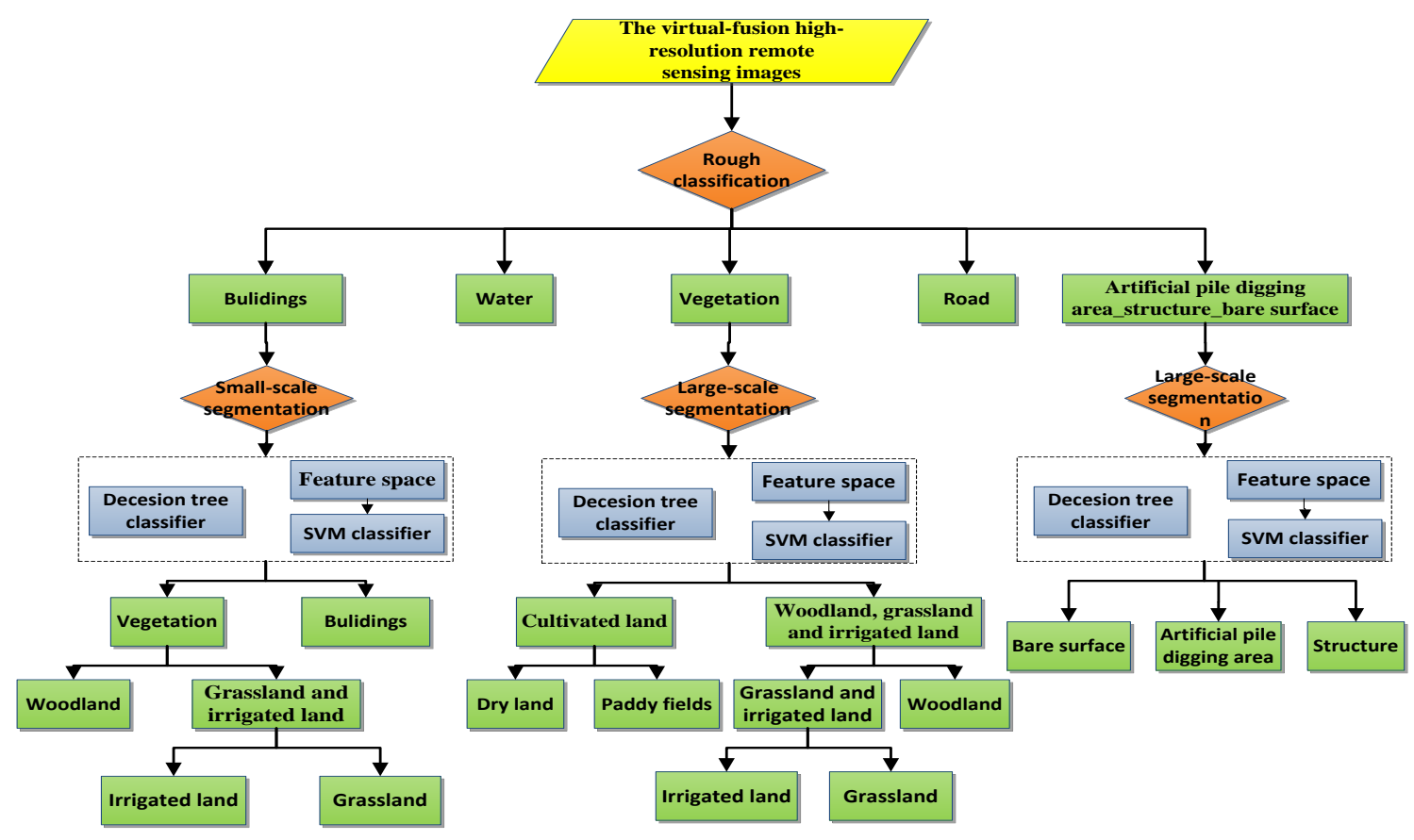

Figure 2. Hierarchical stepwise subdivision classification strategy

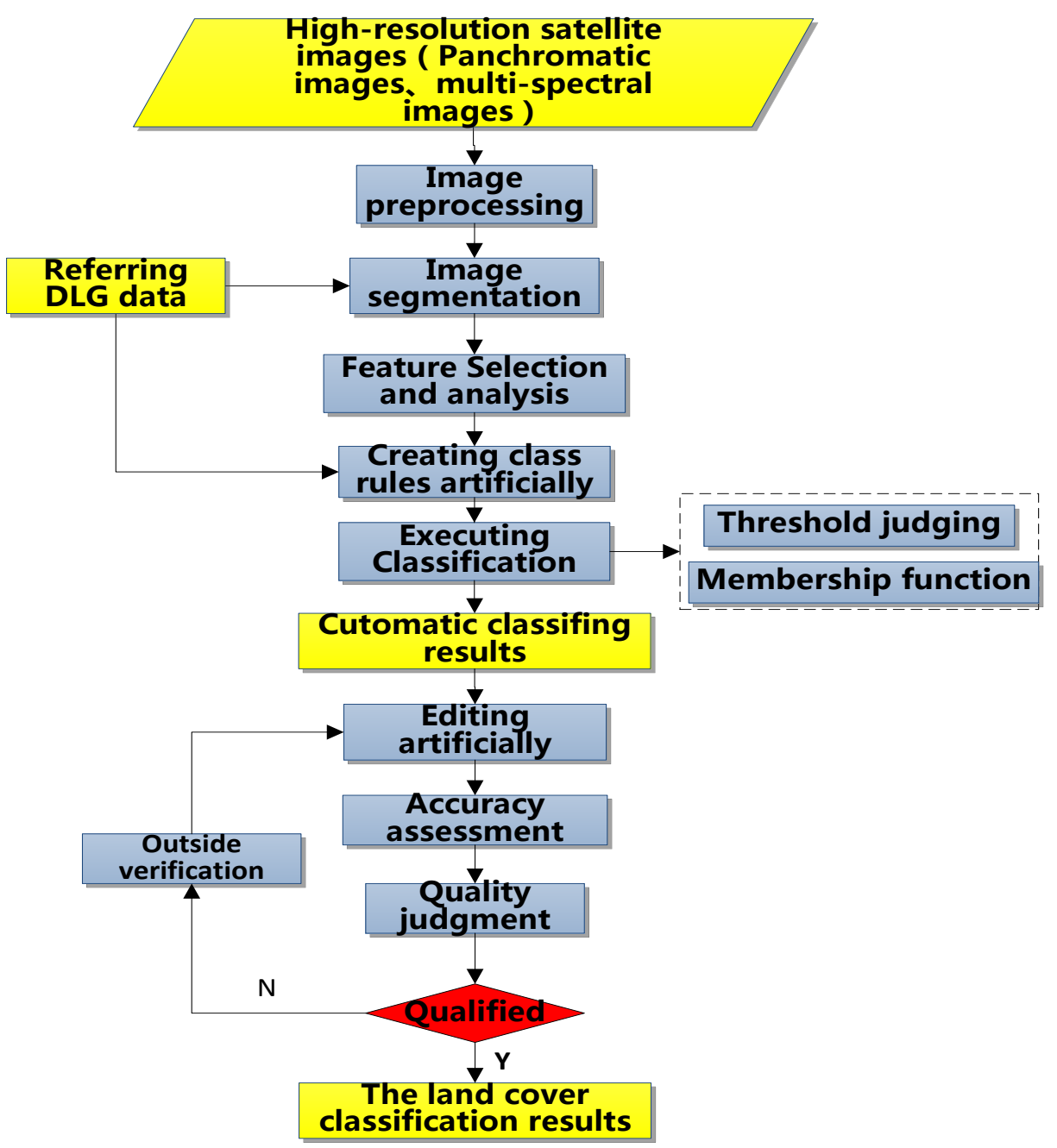

Figure 3. The land cover classification procedure based on eCognition 


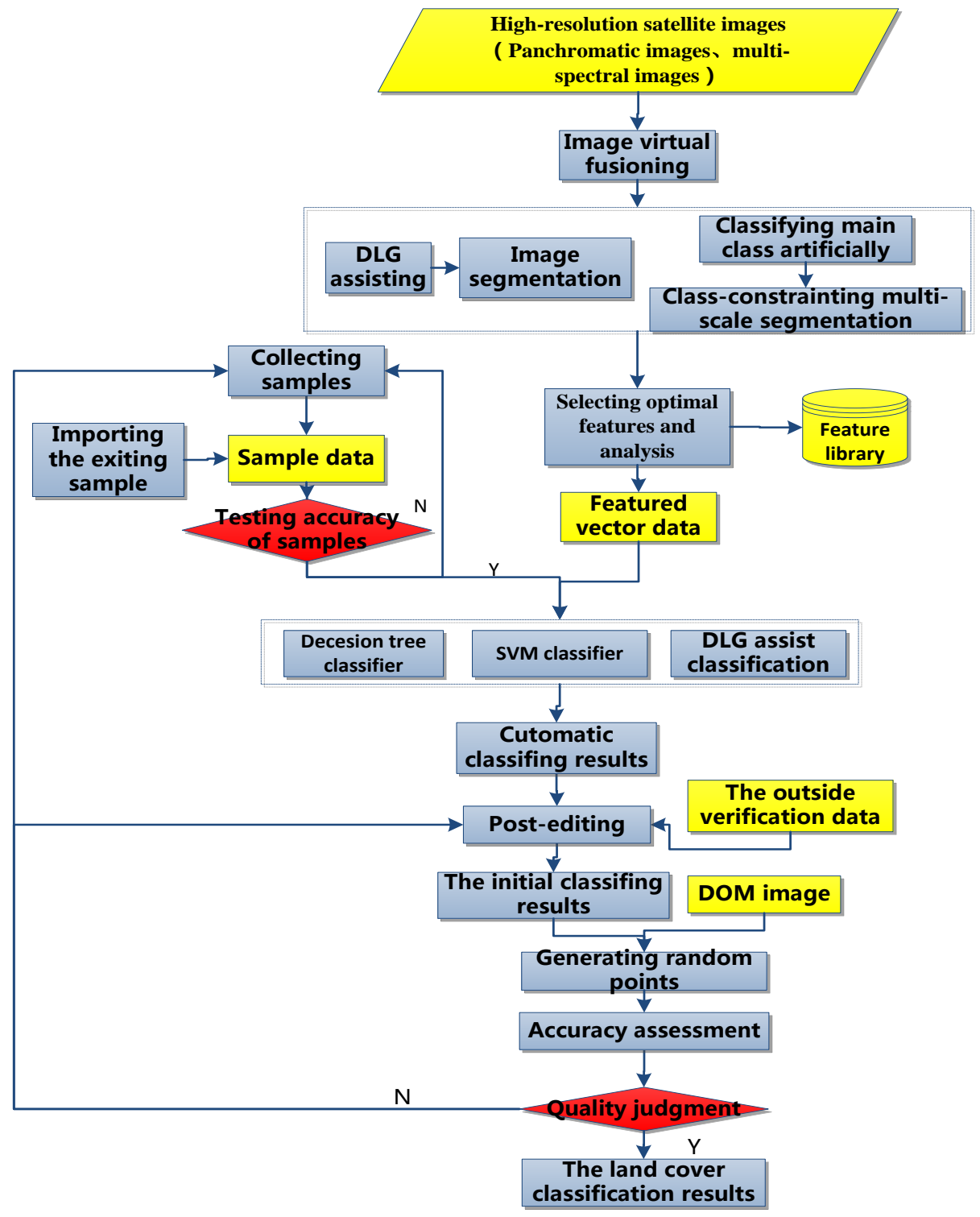

Figure 4. The land cover classification procedure based on FeatureStation GeoEX

\section{CONCLUSIONS AND OUTLOOK}

Land cover classification for geographic national conditions surveying has wide range of information, complex contents. Extracting land cover information timely and accurately has become one of the important tasks in the geographic national conditions surveying project. With the first and second pilot work of the geographic national conditions surveying, some land cover classification schemes for geographic national conditions surveying have been explored,and existing technical methods have been improved and achieved some success. However,the land cover classification accuracy is not high and the workload of post-editing is heavy.Those basic and key issues have yet to be effectively resolved.Therefore, in order to solve this problem, to improve the accuracy of land cover classification furtherly, and to ensure the progress of the geographic national conditions surveying, it needs continued research trials on object-oriented segmentation and classification techniques, classification strategy and workflow.With pilot production experience to assist technical improvements, such as quantifying segmental scale for different types of surface features to achieve scale adaptive technology,optimizing the optimal combination of features for each feature and set the threshold,and customizing a set of land cover classification strategy which has strong reusability and good universality for geographic national conditions surveying, and form cases to guide production.

\section{REFERENCE}

2013. Overall design of geographical conditions monitoring. 2013.Pilot scheme for geographic national conditions surveying(Trial draft).

Zhai C G. 2010b.Study of the Impact of Classification Accuracy Based on Multi-scale. Inner Mongolia Agricultural University,Inner Mongolia

Yan N L, Hwee K L, Andy M. Y. 2008a.Multiresolution segmentation-An optimization approach for high quality multiscale image segmentation. IEEE TRANSACTIONS ON IMAGE PROCESSING, 17(12),pp,2289-2300.

Antonio W.2010a.Using WorldView-2 Vis-NIR MSI imagery to support land mapping and feature extraction using normalized difference index ratios. Spectral Analyst Ball Aerospace \& Technologies Corp. 
International Archives of the Photogrammetry, Remote Sensing and Spatial Information Sciences, Volume XL-7/W1, 3rd ISPRS IWIDF 2013, 20 - 22 August 2013, Antu, Jilin Province, PR China

Gao W. 2010b.The Study of Information Extraetion Teehnology for Remote Sensing Based On Feature Knowledge. China University of Geosciences,Beijing.

Zhou N G. 2012b.Research and System Implementation of A Multi-Classifier Combined Decision Tree Hierarchical Classification Method. Huazhong university of science and technology,Hu Bei.
Wen S. 2011b.Remote Sensing Image Data Object-oriented Classification and Fuzzy Logic Classification Researeh. KunMing university of science and technology, KunMing. Ge Q C,Zhang L H,Yang J. 2009a.Classification of Remote Sensing Images Based on Naive Bayesian Classifier. Remote sensing information,(2),pp, 86-90 